\title{
Adaptive phenological mismatches of birds and their food in a warming world
}

\author{
Marcel E. Visser • Luc te Marvelde • Marjolein E. Lof
}

Received: 8 April 2011/Revised: 28 August 2011/Accepted: 4 October 2011/Published online: 3 December 2011

(C) The Author(s) 2011. This article is published with open access at Springerlink.com

\begin{abstract}
Climate change has profound ecological effects in birds, with the clearest effect a shift in timing, or phenology, of avian reproduction. To assess the consequences of these shifts, we performed a literature search and compared the rates of phenological change in the reproduction of birds with that of the food for their offspring. While in some areas the rate of change of the birds and their food was similar, there were also areas where the birds' shift lagged behind that of their food. In these cases, this will lead to a phenological mismatch, which will affect the fitness of the brood. There are two hypotheses explaining why climate change leads to mismatched reproduction: either the cues used no longer accurately predict the peak in food abundance (the cues hypothesis) or the fitness costs of egg production and/or incubation of laying early enough to match reproduction are substantial in early spring and are not compensated by the fitness benefits of a better matched reproduction (constraint hypothesis). In the latter case, the phenological mismatch is adaptive. We present a simple mathematical model to show that this may be the case if there are fitness costs of egg laying and/or incubation under cold conditions and if the temperatures that determine the peak in food abundance increase stronger than the temperatures affecting the costs of egg laying and incubation, as is the case in the Netherlands. Whether or not a phenological mismatch is adaptive has important consequences for natural selection acting on timing of
\end{abstract}

Communicated by John Wingfield.

M. E. Visser $(\square) \cdot$ L. te Marvelde · M. E. Lof Department of Animal Ecology,

Netherlands Institute of Ecology (NIOO-KNAW), P.O. Box 50, 6700 AB Wageningen, The Netherlands e-mail: m.visser@nioo.knaw.nl reproduction. If the mismatch is not adaptive, timing of reproduction will be under direct natural selection, while, if the mismatch is adaptive, selection is likely to be on the costs of egg production, possibly on egg size or adult size. In all cases, a mismatch is expected to have negative population consequences and, especially when the mismatch is adaptive, these consequences cannot be reduced by a response to natural selection on timing directly. This makes experimental studies on laying date, which can determine whether the mismatch is adaptive, of crucial importance.

Keywords Timing - Phenological mismatch - Climate change $\cdot$ Reproduction

\section{Zusammenfassung}

Adaptive phänotypische Fehlanpassungen zwischen Vögeln und ihrer Nahrung in Zeiten der Erderwärmung

Der Klimawandel hat tiefgreifende Auswirkungen auf die Ökologie von Vögeln, wobei der deutlichste Effekt eine Verschiebung des Timings, oder der Phänologie, der Fortpflanzung ist. Um die Konsequenzen einer solchen Verlagerung zu untersuchen haben wir eine Literatursuche durchgeführt und die Rate der phänologischen Veränderung im Brutverhalten der Vögel mit denen der Nestlingsnahrung verglichen. Während in manchen Fällen die Veränderungsraten der Vögel und Nahrungsquelle ähnlich waren gab es auch Nahrungsketten in denen die Rate der Vögel hinter der ihrer Nahrung zurückblieb. Daraus resultiert eine phänologische Fehlabstimmung (mismatch), die die Fitness der Brut beeinträchtigt. Zwei Hypothesen können erklären warum der Klimawandel zu dieser zeitlichen 
Fehlabstimmung im Timing der Fortpflanzung führt: Entweder die verwendeten Signale sagen nicht mehr akkurat den Zeitpunkt maximaler Nahrungsabundanz voraus (cues-Hypothese), oder aber die Fitness-Kosten einer ausreichend frühen Eiproduktion und/oder Inkubation sind im frühen Frühjahr so beträchtlich, dass sie nicht ausreichend durch die Fitness-Gewinne einer gut getimten Fortpflanzung ausgeglichen werden (constraints-Hypothese). Im letzten Fall ist eine phänologische Fehlabstimmung adaptiv. Wir stellen hier ein einfaches mathematisches Modell vor, welches verdeutlicht, dass dies der Fall sein könnte, wenn es Fitness-Kosten der Eiproduktion und/oder Inkubation unter kalten Temperaturbedingungen gibt und wenn die Temperaturen, die den Höhepunkt der Nahrungsabundanz beeinflussen, stärker ansteigen als die Temperaturen, die die Kosten der Eiproduktion und Inkubation bestimmen, wie es in den Niederlanden der Fall ist. Ob eine phänologische Fehlabstimmung adaptiv ist hat bedeutende Auswirkungen auf die natürliche Selektion des Fortpflanzungs-Timings. Bei einer nichtadaptiven Fehlabstimmung steht das Timing unter direkter natürlicher Selektion, andernfalls findet Selektion auf die Kosten der Eiproduktion statt, möglicherweise auch auf die Eigröße oder Größe der adulten Vögel. In jedem Fall wird erwartet, dass eine zeitliche Fehlabstimmung negative Auswirkungen auf die Population hat, und besonders wenn diese Fehlabstimmung adaptiv ist, können Konsequenzen nicht durch eine direkte Reaktion auf die natürliche Selektion des Timings reduziert werden. Diese Tatsache unterstreicht die Bedeutung experimenteller Studien von Legedaten, welche aufklären können, ob eine Fehlabstimmung adaptiv ist.

\section{Introduction}

Climate change has a number of well-documented ecological effects on birds. It has led to range shifts in both breeding areas (Thomas and Lennon 1999) and, for short and medium distance migrants, wintering areas (Visser et al. 2009; la Sorte and Thompson 2007), to shifts in body mass or size (Husby et al. 2011a; Teplitsky et al. 2008) and to changes in population size (Saether et al. 2000; Jenouvrier et al. 2009; Both et al. 2006). The most striking effect of climate change is, however, on timing. Long distance migrants now migrate earlier to their wintering areas, as has been shown from data on autumn migration at banding stations (Jenni and Kéry 2003; van Buskirk et al. 2009), while medium distance migrants pass through later (Jenni and Kéry 2003; van Buskirk et al. 2009).

Climate change also has a strong impact on avian timing of reproduction (Crick et al. 1997; Dunn 2004). For instance, Dunn (2004) showed that 45 out of 57 bird species (79\%) breed earlier in years with high temperatures in the pre-egg laying period. Therefore, with increasing temperatures, many bird species have shifted their seasonal timing, or phenology, of reproduction during the last decades. But there is ample variation in shifts in avian breeding date among species; larger species or species whose food supply is less affected by climate change (e.g. fish-eating herons) have responded less to climate change. Also, within species, there is spatial variation in the shift in timing of reproduction as has been documented for Great Tits (Parus major) and Blue Tits (Cyanistes caeruleus) (Visser et al. 2003) and Pied Flycatchers (Ficedula hypoleuca) (Both et al. 2004). For the Pied Flycatcher, this variation correlated well with spatial variation in the increase in local temperature (Both et al. 2004), while for Great and Blue Tits variation in the number of broods produced per year, which likely depends on the forest vegetation composition, explains part of the variation (Visser et al. 2003).

How should we interpret these shifts in breeding phenology? On the one hand, they can be regarded as a bad sign: apparently climate change has already such an impact that its effects can be clearly observed in wild birds. But the shifts can also be regarded as a good sign: climate is changing and the birds are changing as well, to keep in pace with their environment. To distinguish between these two interpretations,we need some sort of a yard-stick: how much should species shift their timing of reproduction to keep up with their changing environment (Visser and Both 2005)?

Shifts in phenology due to climate change vary widely among groups of organisms (plants, insects, birds, etc.) but also within these groups (Visser and Both 2005; Parmesan 2006; Thackeray et al. 2010). This makes it likely that birds are shifting at different rates (faster or slower) than other species in their food chain, either their food or their predators. As in many species phenological synchronisation of peak food abundance and offsprings' needs is a crucial determinant of fitness (Thomas et al. 2001; Visser et al. 2006), a potential yard-stick for shifts in avian timing or reproduction is the phenology of the food which is used to raise the nestlings. The key comparison is between the phenological shift in avian reproduction and the shift in the peak food abundance. In the next section, we review the avian literature on this comparison.

\section{Phenological mismatches}

We searched the literature for papers on avian reproduction which report both the rate at which the timing of avian reproduction is shifting over the years and the rate at which the phenology of the food for the nestlings of these species is shifting. For this, we looked at all 466 papers which cited either Visser et al. (1998), Visser and Both (2005) or Sanz (2002), as well as the references cited by these 466 papers, 
in order to select papers that report long-term studies on bird and food phenology (or host phenology in the case of cuckoos). Only in 11 papers were rates of change of both tropic levels described but some of these described multiple study areas or multiple species, resulting in information on 18 pairs of phenology changes (Table 1). All phenology rates of changes were expressed as days per year (if the shift was not expressed in days per year in the paper we calculated this). We also determined whether these papers reported fitness effects from the mismatch. Such negative fitness effects were mostly reported as negative selection differentials over the study period, reduced breeding success or reduced nestling growth over the study period. In four studies, no fitness changes over the study period were provided.

Most of the bird species for which data are available are insectivorous forest passerines (Great Tit, Blue Tit, Pied Flycatcher, Collared Flycatcher Ficedula albicollis; 13 out 18 pairs). In the Netherlands, Great Tits and Pied Flycatchers have advanced their egg laying, but at a slower rate than the advancement of the caterpillar food peak (Visser et al. 1998; Both and Visser 2001), resulting in stronger selection for early laying over the last decades. A Belgian population of Blue and Great Tits have advanced fledging date to the extent that they matched the advancement of their food, without negative fitness effects (Matthysen et al. 2011). Here, phenology of their food was measured indirectly via a temperature-dependent formula used for the Dutch population (Visser et al. 2006; -0.55 days/year) and via chick mass (mass for 10-day-old chicks is predicted to be highest for those well timed with the food peak; -0.72 days/year). Charmantier et al. (2008) showed that Great Tits in the UK, which always have been mismatched, are shifting at more or less the same rate as the caterpillar food peak. Also, in three populations in the Czech Republic, Great Tits and Collared Flycatchers have advanced egg laying to the same extent as the caterpillar advancement (Bauer et al. 2010). Sanz et al. (2003) measured advancement of spring via satellite images from which information on the amount green vegetation advanced over time can be extracted (NDVI index), which correlates with the food peak. The occurrence of green vegetation advanced, but Pied Flycatchers did not breed earlier, causing a reduced breeding success over the study period.

There are also a number of studies on species other than insectivorous forest passerines. Sparrowhawks (Accipiter nisus) in the Netherlands have not advanced reproduction, thus becoming increasingly mismatched with their food source, the fledglings of passerines which have shifted (Both et al. 2008). A similar pattern is shown for the Danish Sparrowhawks (Nielsen and Moller 2006). Unfortunately, in both Sparrowhawk studies, changes in fitness measured over the study period were not reported. Thick-billed Murres (Uria lomvia) start breeding when the ice which covers their breeding grounds has disappeared. Gaston et al. (2009) showed that median egg laying dates in Thick-billed Murres have advanced, but at a slower rate than the advancement of the ice melt. When food conditions are favourable, Murres spend more time at the colony, and therefore the authors interpret the date of peak attendance as the time when suitable prey are most readily available to the Murres in the waters surrounding the colony. Finally, an example where the yard-stick is not food but the availability of hosts. Cuckoos (Cuculus canorus) in Europe have advanced their arrival to their breeding grounds in 20 different locations. Cuckoos lay their eggs in nests of host species, which can be either long or short distance migratory passerines. Here, both Cuckoos and long distance migratory host passerines have advanced arrival to the breeding grounds equally, but short distance migratory hosts have advanced arrival to the breeding grounds more strongly over the last six decades (Saino et al. 2009).

It is likely that more data on shifts in avian timing of reproduction and of their prey are available but that these data are not published, at least not in a single paper. One problem hampering such comparisons is that data on different taxonomic groups are often collected by different research groups. Potential bird species for which shifts in phenology are documented and for which it is possible that data on their food phenology are also available are Black Grouse (Tetra tetrix), where the offspring feed on small caterpillars in bilberry (Ludwig et al. 2006, 2010), in so-called meadow species, such as Lapwings (Vanellus vanellus) and Black-tailed Godwits (Limosa limosa), where the offspring feed on invertebrates living in the grassland vegetation (Schekkerman and Beintema 2007), and in sea birds, such as Puffins (Fratercula arctica), which feed on small fish, such as Herring, Sandeel and Capelin (Durant et al. 2003). Comparisons of the shifts in phenology for these species would make a valuable contribution to the pattern in Fig. 1.

It is clear that there is ample variation in the rate at which populations shift their timing (Table 1; Fig. 1), but note that all but two populations shift (i.e. have a negative value on the $y$-axis of Fig. 1). Interestingly, this seems mainly due to spatial variation rather than due to variation between species at the same location (cf. Visser et al. 2003; Both et al. 2004). When we compare these shifts in phenology of birds with the shift of their prey, there is also ample variation (Fig. 1). In a large number of populations, these two shifts are similar; the birds shift as fast in their phenology as their prey. However, there are also populations where the birds lag behind the shift in their prey. In these populations climate change leads to a phenological mismatch. Again, this seems more to do with geographic location rather than species as there is quite some variation within species in how much these rates differ. 


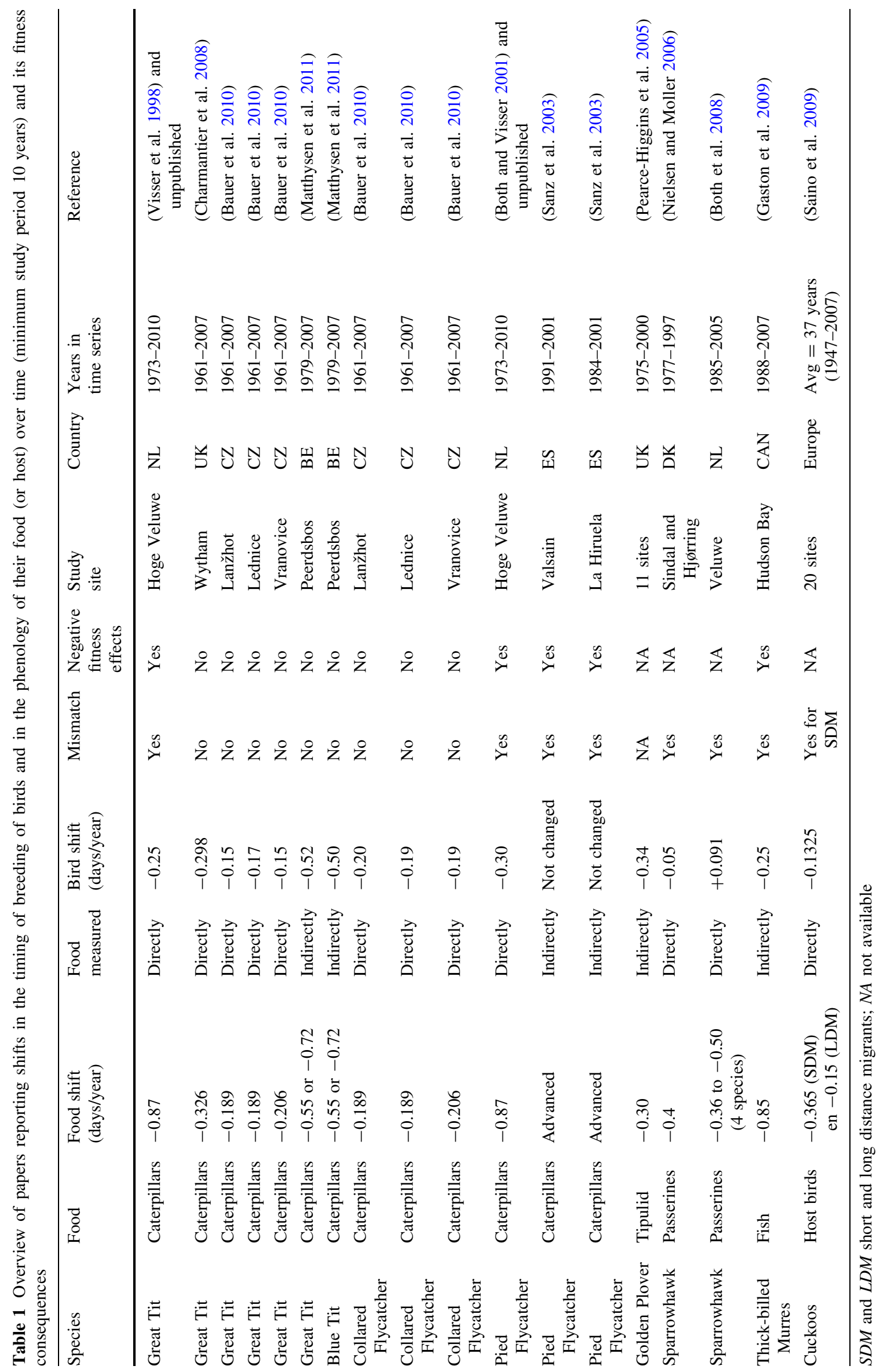




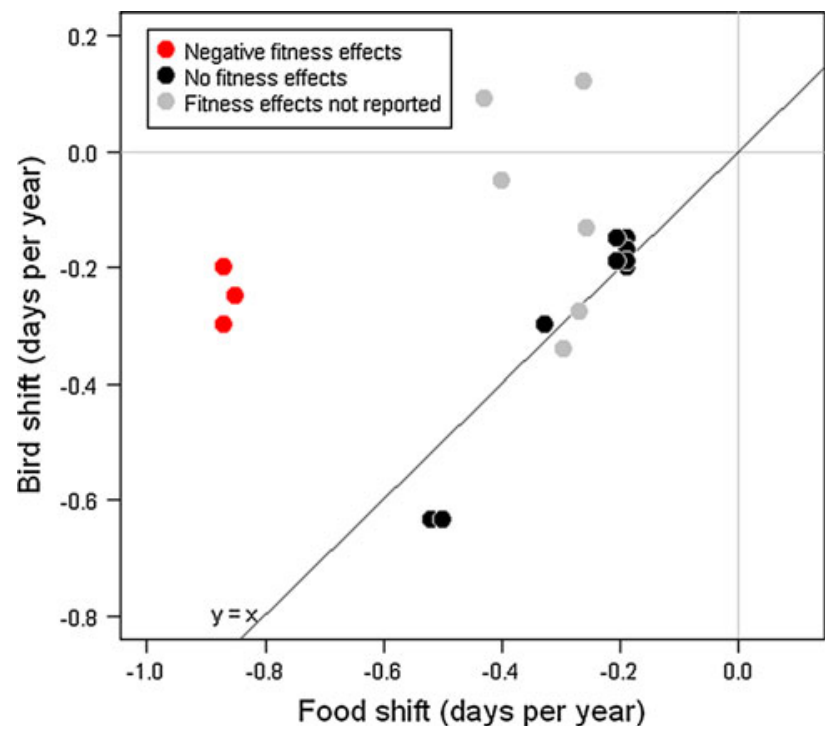

Fig. 1 Visualization of a literature review showing differences in the rate of bird phenology and food phenology. Solid line is where the change in bird phenology equals the change in food phenology. Points close to the line are expected to show no negative effects (black dots), whereas points far from the line (where bird and food phenology are mismatched) are expected to show negative effects (red dots)

It is striking that none of the points in Fig. 1 lay substantially below the line, i.e. in none of the cases is the birds' phenology shifting faster than that of their prey. Of the studies that report possible fitness consequences, there were only three cases with negative fitness consequences (in terms of fitness return from the brood). These were also the only cases where the preys' phenology is shifting much faster than the birds', resulting in an increased mismatch.

In Fig. 1, we compare the shift in laying date with that of the food, but it is obviously the match between hatching date rather than laying date which matters. However, although there may be some phenological adaptation via clutch size, the duration of incubation and even in rate of chick development (Matthysen et al. 2011), the possibility to speed up or delay the breeding is limited, therefore laying date remains the key trait determining the degree of mismatch between offsprings' needs and food availability.

Why would climate change lead to a phenological mismatch? There are two hypotheses: the cues hypothesis and the constraint hypothesis.

Many bird species are phenotypically plastic in their seasonal timing: the same individual will lay at different times when the annual conditions differ. Birds use cues, such as photoperiod and temperature, to time their reproduction (Visser et al. 2010). However, the climate variables that are used as cues occur earlier in the year than the climate variables that determine the peak in food abundance. If climate change is then leading to a stronger increase in, for instance, the temperatures that affect the food peak than the temperatures that are used as cues, this will lead to maladaptive plasticity and a phenological mismatch. This may be especially true for photoperiod as this is a cue that is obviously not changing due to climate change while it is a cue which plays an essential role in seasonal timing. This is what we term the cues hypothesis: the cues that are used are no longer accurately predicting the phenology of the food peak.

An alternative hypothesis is based on the fact that egg production and incubation is costly, both in terms of energy (Stevenson and Bryant 2000; Nilsson and Raberg 2001) and fitness (Monaghan et al. 1998; Visser and Lessells 2001). This so-called constraint hypothesis explains phenological mismatches from the fitness costs of producing eggs early in spring, under harsher conditions, which are not compensated by the fitness benefits of a better phenological match. Under this hypothesis, phenological mismatches may be adaptive. In the next section, we will explore this possibility in more detail.

\section{Adaptive mismatches}

Ecologists have long been aware that egg laying and incubation is costly. A seminal paper by Perrins (1970) argues that birds are simply unable to reproduce very early in spring as there will be a date at which they are so constrained by the resources available that they are unable to gather enough resources to produce an egg. A slightly different way to look at this is that, although birds would be able to produce an egg very early in spring, the fitness costs of doing so (in terms of, for instance, survival of the female) will be so high that the birds will refrain from laying this early. In this view, laying dates are a compromise between fitness costs of laying early and fitness benefits from a phenological match between the food peak and the offsprings' needs (Visser and Lambrechts 1999).

There are now ample data on there are major costs of egg laying and incubation. This has been shown in freeliving birds by using doubly labelled water to calculate the Daily Energy Expenditure (DEE) of birds laying or incubating under warm or under cold temperatures. The energetic costs of both laying (Stevenson and Bryant 2000; te Marvelde et al. 2011b) and incubation (de Heij et al. 2008) are higher at lower temperatures. This is possibly a consequence of increase thermoregulation under colder conditions, lower food availability, more effort needed to find food independent of its availability, or a combination of all these. There have also been fitness costs of egg laying demonstrated: birds that are experimentally manipulated to lay more eggs had a lower survival (Visser and Lessells 2001) or were less able to rear their offspring (Monaghan et al. 1998). There are thus clear costs of reproducing under cold and harsh conditions. 
The fitness return (i.e. the number of surviving offspring produced) from a brood strongly depends on the match between birds' reproduction and the food peak. A number of studies have shown that the energetic costs of rearing offspring depending on the match with the food peak (Thomas et al. 2001; Verhulst and Tinbergen 2001; te Marvelde et al. 2011c). The number and conditions of fledglings produced also depends on the phenological match: both laying too early and laying too late has fitness consequences (Visser et al. 2006).

As the phenology of both the birds and the food peak are temperature sensitive (Visser et al. 2006), the phenological match between birds and their food also depends on temperature. The timing of the food peak depends on the temperature in a period which also includes the time the birds are already laying and incubating, and it is the temperature in this period which has a large effect on the degree of mismatch (van Noordwijk et al. 1995). This is especially relevant as climate change may not be shifting temperature in a uniform way (Houghton et al. 2001). Some periods in spring warm up faster than others (Visser et al. 1998), and there is large geographical variation in this (Both and te Marvelde 2007; Visser et al. 2003). This means that at least in some populations the temperatures that affect the food peak, and the phenological match, increase more than the temperatures that affect the cost of egg production and incubation.

There are thus costs of being mismatched, but there are also costs of laying under cold conditions. It may therefore be adaptive to lay somewhat later than the date that would maximise the fitness return from the brood (i.e. the number of surviving offspring), especially when the weather conditions improve during the season and therefore the fitness costs of egg laying and incubation decline. However, laying later comes at the price of being mismatched at the time of chick feeding (cf. Visser et al. 1998; Visser 2008; Jonzen et al. 2007 for migrant birds). To formalise this hypothesis, and thereby investigate whether a mismatch between the food peak and timing of reproduction could be advantageous, we developed a simple mathematical model as a proof of concept. In this model, adult survival depends on temperatures during early spring, and the timing of the food peak depends on temperatures during late spring. We use a sigmoid function for the temperature-dependent survival of the adult (Fig. 2, dotted line). The survival probability during egg laying or incubation of an adult is low very early in the season, when temperatures are low and very limited food is available in the environment, and increases to very high values later in the season, when temperatures are higher and the costs of egg laying and incubation are lower. Furthermore, we assume that the reproductive value of the brood is the highest when they are matched with the food peak (Fig. 2, dashed lines).
We assume that a bird has a brood of 9 young, and that recruitment probability of a single young is 0.2 when they are perfectly matched with the food peak. To get total fitness, we add up the survival probability with the fitness return from the brood (number of recruiting offspring $\times 0.5$ to correct for relatedness).
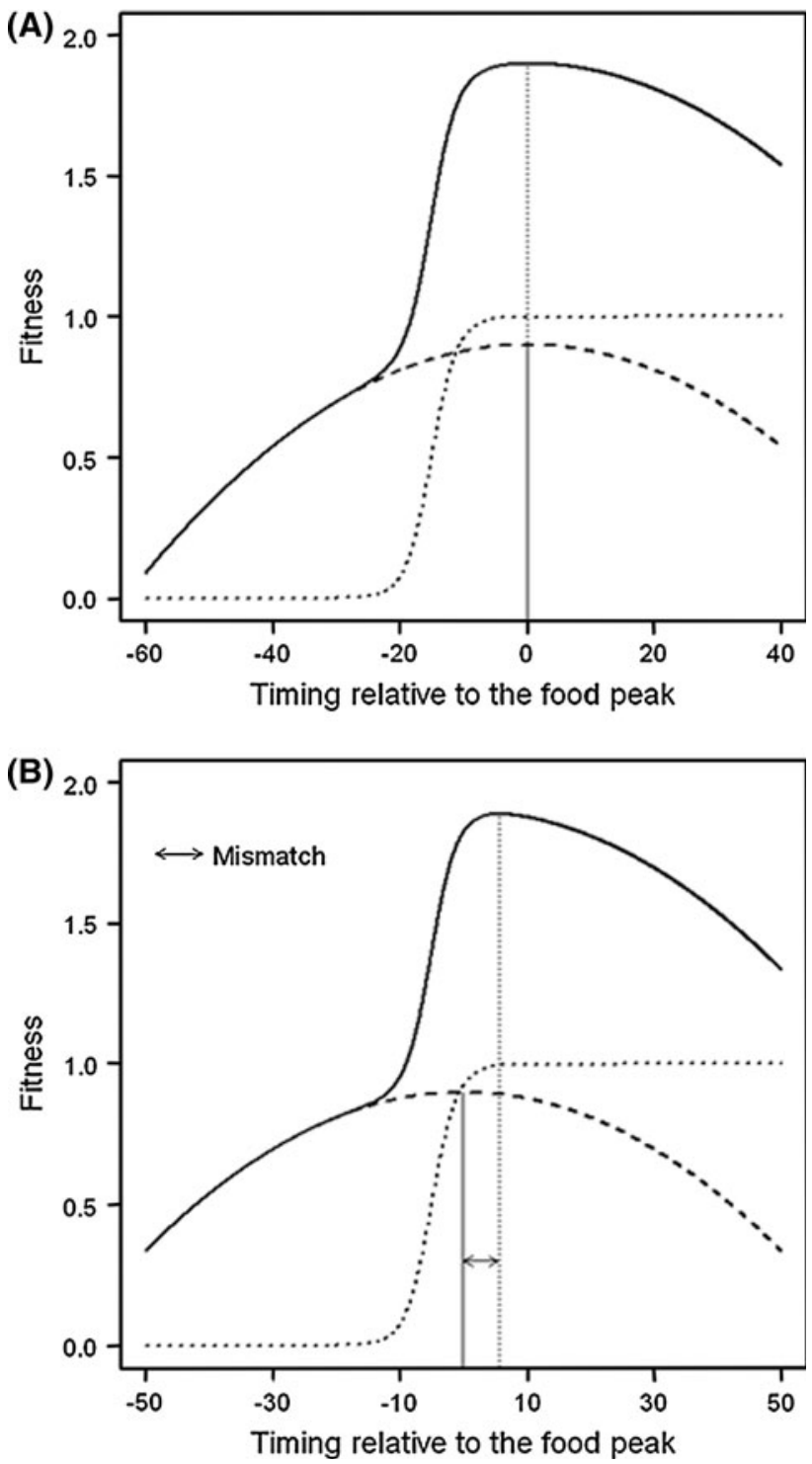

Fig. 2 A model on an adaptive phenological mismatch. The survival probability of the adult during egg laying or incubation (dotted line), the value of the young (dashed line) and the total fitness (solid line) depend on the timing of reproduction relative to the food peak. a The optimal timing of reproduction is such that there is a match between the phenology of the birds and their food. b The food peak has shifted 10 days forwards compared to (a) due to higher temperatures in late spring while the survival probability of the adults have remained the same compared to (a), as temperatures in early spring have not increased. In this case, birds are optimally mismatched. The vertical lines indicate the optimal reproductive value of the young (maximum at food peak - solid line) and the maximum total fitness (dotted line): in (a) this is at the food peak, in (b) this is 6 days after food peak (the adaptive mismatch is indicated) 
If temperature increases in late spring, causing the food peak to advance, but not in early spring, so that the conditions during egg laying and reproduction stay the same, it can be optimal to be mismatched (Figs. 2 and 3; Table 2). Being mismatched reduces the reproductive success, but increases adult survival and the sum of the two leads to a higher fitness than when a bird is matched with the food peak. When the curves describing adult survival depending on laying date and fitness return from the brood depending on laying date shift with 10 days relative to each other, the birds' optimal laying date shift not 10 but just 6 days (Table 2; Fig. 2). Obviously, these values depend on the actual parameter values of the model, but the general point is that birds should not fully follow the shift in the phenology of their food and thus become adaptively mismatched.

Jonzen et al. (2007) developed a model similar to ours but for the optimal time of arrival in migratory birds. In

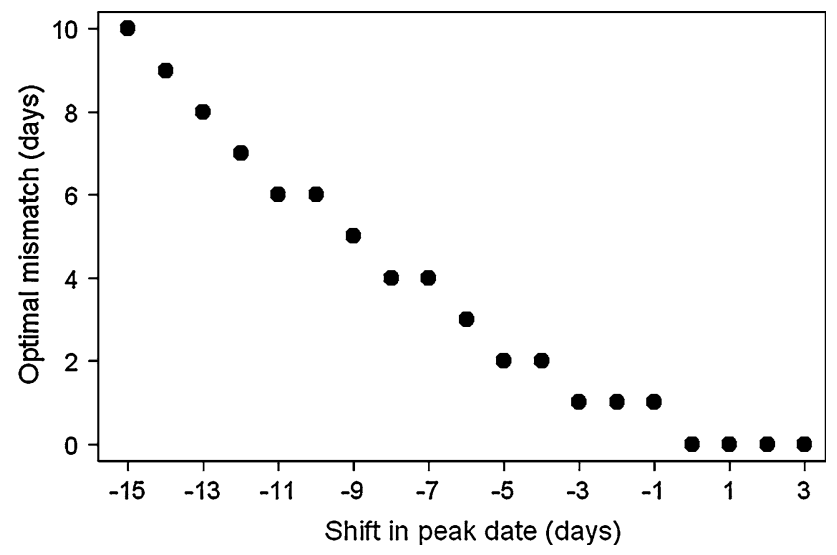

Fig. 3 Results from a model on an adaptive phenological mismatch. The optimal mismatch, given in days a bird should breed later than when matched with the food peak to obtain maximal fitness plotted against the shift of the food peak in days

Table 2 Results from a model on an adaptive phenological mismatch (Fig. 2)

\begin{tabular}{llll}
\hline $\begin{array}{l}\text { Shift in food peak } \\
\text { (days) }\end{array}$ & $\begin{array}{l}\text { Date of maximum } \\
\text { fitness }\end{array}$ & $\begin{array}{l}\text { Optimal } \\
\text { mismatch }\end{array}$ & $\begin{array}{l}\text { Maximum } \\
\text { fitness }\end{array}$ \\
\hline 5 & 5 & 0 & 1.900 \\
0 & 0 & 0 & 1.899 \\
-5 & -3 & 2 & 1.897 \\
-10 & -4 & 6 & 1.888 \\
-15 & -5 & 10 & 1.871 \\
\hline
\end{tabular}

Fitness for birds that match their timing to the phenology of their food and of adaptively mismatched birds. The optimal mismatch is the amount of days that a bird should breed later than the shifted food peak to obtain the maximal fitness. Fitness is the sum of the adult survival during egg laying and incubation and the reproductive value of the brood ( 0.5 times the number of recruits produced) their model, the optimal arrival date is a trade-off between competition for territories, which favours early arrival, and an instantaneous mortality rate that declines over the season, which favours late arrival. Furthermore, the reproductive success is a function of the amount of food that the migratory bird acquired during the limited breeding season. Similar to our model, they also found that the shift in the optimal arrival date is always less than the shift in the resource peak date, as long as the probability of survival to breeding increases when birds arrive later. Furthermore, they show that the wider the food peak, the weaker the response to a shift in the phenology of the food peak.

In our conceptual model, the temperature affecting the costs of egg laying and incubation in early spring does not increase while the temperature in late spring affecting the food peak does increase. But this not need to be the case. In some areas, both these temperatures may increase equally fast or in some species the temperature period affecting reproduction and the food peak phenology may be very similar. Note that it may even be the case that differential shifts in temperature due to climate change may also relax the costs of egg laying and incubation (when the temperature affecting the costs increase stronger than the temperatures affecting the food peak phenology) and thus may reduce the mismatch in populations where there used to be an adaptive mismatch (Cresswell and McCleery 2003).

Testing adaptive mismatches

Experiments are needed to test which of the two hypotheses explaining why climate change may lead to mismatched reproduction, the cues hypothesis and the constraint hypothesis, is true, as under the latter hypothesis the birds may adaptively be mismatched. One way to distinguish between them is to experimentally shift the birds to an earlier laying date and then measure fitness. The predictions of the cues hypothesis is that the experimental birds will have the highest fitness while the constraint hypothesis predicts that the controls will have the highest fitness (see Fig. 4). Experiments where the costs of egg
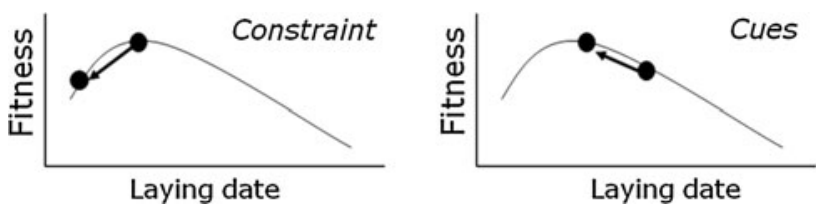

Fig. 4 Predictions of the effect of experimentally shifting laying date earlier (arrow) on fitness (the number of surviving offspring and the female's own survival combined). Note that these are curves depicting the fitness curve for individual females. Under the constraint hypothesis, the fitness of the experimental animals will be lower than the control, while under the cues hypothesis, the fitness of the experimental animals will be higher 
laying or incubation are affected, like heating nest boxes (Yom-Tov and Wright 1993; Nager and Van Noordwijk 1992) or supplemental feeding of birds in the pre-laying period (Nager et al. 1997), are likely to be inconclusive as these experiments not only affect the energetic costs (which under the constraint hypothesis is predicted to advance laying date) but also the cues used by the birds (which under the cues hypothesis is predicted to advance the laying date).

However, the question how to manipulate laying date in the wild is not trivial as there are drawbacks to all of the methods used to do this (see review by Verhulst and Nilsson 2007), like inducing replacement clutches (Verhulst et al. 1995) or swapping early and late clutches during incubation (Verboven and Verhulst 1996). One experimental technique that shifted laying dates that did not suffer from these drawbacks was an elaborate experiment where in year 1 birds were provided with ample food during incubation (and the controls during chick feeding) which then in year 2 (when there was no experimental manipulation) laid earlier (Gienapp and Visser 2006), thereby paying the full costs of early laying. Unfortunately, the sample sizes were too small to measure fitness (number of recruiting offspring produced plus adult survival) to determine whether the fitness of the experimental birds was higher than that of the controls. Another type of manipulation which seemed promising is taking wild birds indoors for 1 day, exposing them for a single day to a long photoperiod, and then releasing them again in the wild. While in captivity this treatment led to an early gonadal growth, in the wild the experimental birds did not lay earlier (te Marvelde et al. 2011a). Thus, at present, no good experimental tests of the hypotheses explaining why climate change may lead to mismatched reproduction are available.

\section{Consequences of adaptive mismatches}

Climate change may have caused birds to become mismatched with their food. When this is because the cues involved in timing of reproduction no longer accurately predict the food peak, birds are actually mistimed: their fitness would be higher if they had laid earlier (cues hypothesis). In that case, climate change will lead to selection on seasonal timing: early laying birds will have a higher fitness than late laying birds and hence natural selection will favour early laying (Visser et al. 1998). Seasonal timing is also known to be heritable (Husby et al. 2011b; Sheldon et al. 2003; Gienapp et al. 2006), and recently it has also been shown that there is genetic variation in cue sensitivity (Visser et al. 2011; Schaper et al. 2011). This genetic variation, in combination with the increased selection for earlier laying, will lead to a genetic change, or micro-evolution, in seasonal timing. Potentially, this could restore the phenological match, but whether or not this will happen strongly depends on the rate of microevolution relative to the rate of climate change (Visser 2008; Husby et al. 2011b).

If the phenological mismatch is actually adaptive, because the fitness costs of producing eggs earlier do not outweigh the fitness benefits of being matched (the constraint hypothesis), birds are mismatched but not mistimed. Natural selection will thus not select for laying earlier given the constraints acting on egg production and incubation. However, there will be selection on these costs, for instance via selection for smaller eggs or for a smaller body size of the bird (Husby et al. 2011a; Haywood and Perrins 1992). If natural selection has led to a response in the traits then the optimal laying date will shift in the direction of a better phenological match (Visser 2008).

Another scenario in which the mismatch can be reduced is when, due to climate change, there is an increase in the temperatures affecting the costs of egg production and incubation leading to a decrease in these costs. In that case, laying date will advance simply because of phenotypic plasticity. The paradox is that further climate change could restore the phenological match provided that the temperatures in early spring increase but not in late spring, i.e. the opposite pattern of what has happened in the Netherlands.

If the rate of micro-evolution is too low and if the increase in early spring temperature keeps lagging behind the increase in temperature late in spring, the phenological mismatch will persist. This is likely to have negative effects on population viability, as was shown for the Pied Flycatcher (Both et al. 2006). Even under the constraint hypothesis, where birds may be mismatched but not mistimed, there will be a cost in term of offspring productivity: the more mismatched the lower the fitness (Table 2) even though birds cannot increase their fitness by laying earlier or later. This resembles the situation where climate change leads to a deterioration of the habitat but not to mismatched reproduction: no selection for earlier laying but still a decline in fitness (see fig. 1 in Visser 2008). Thus, even in the case of an adaptive mismatch, there is a potential negative effect on population viability due to climate change. In fact, this is a situation which is likely to have even more severe population consequences as, in the case of an adaptive mismatch, there will be no response to selection on timing directly and hence natural selection will not reduce the negative effects of the mismatch on population viability.

\section{Concluding remarks}

Climate change is affecting the phenology of many species and can lead to a phenological mismatch between the 
offsprings' needs of birds and the peak in food abundance. While at a first glance this appears to be maladaptive, this may not be the case if there are fitness costs of egg laying and/or incubation under cold conditions, as has been demonstrated to be the case, and if the temperatures that determine the peak in food abundance increase stronger than the temperatures affecting the costs of egg laying and incubation, as is the case in the Netherlands. In that case, earlier laying may lead to an increase in fitness costs that are not compensated by the fitness benefits of a better phenological match. As an adaptive mismatch has evolutionary and ecological consequences, it is important to test the adaptive mismatch hypothesis by experimental manipulation of laying date in the wild.

Acknowledgments MEV would like to thank the scientific programme committee of the XXV International Ornithological Congress for their invitation to present our research. Anne Charmantier kindly provided data for Pirio and Muro that were included in Fig. 1. MEV is supported by a NWO-VICI grant.

Open Access This article is distributed under the terms of the Creative Commons Attribution Noncommercial License which permits any noncommercial use, distribution, and reproduction in any medium, provided the original author(s) and source are credited.

\section{References}

Bauer Z, Trnka M, Bauerova J, Mozny M, Stepanek P, Bartosova L, Zalud Z (2010) Changing climate and the phenological response of great tit and collared flycatcher populations in floodplain forest ecosystems in Central Europe. Int J Biometeorol 54(1):99111. doi:10.1007/s00484-009-0259-7

Both C, te Marvelde L (2007) Climate change and timing of avian breeding and migration throughout Europe. Clim Res 35:93-105

Both C, Visser ME (2001) Adjustment to climate change is constrained by arrival date in a long-distance migrant bird. Nature 411(6835):296-298

Both C, Artemyev AV, Blaauw B, Cowie RJ, Dekhuijzen AJ, Eeva T, Enemar A, Gustafsson L, Ivankina EV, Jarvinen A, Metcalfe NB, Nyholm NEI, Potti J, Ravussin PA, Sanz JJ, Silverin B, Slater FM, Sokolov LV, Torok J, Winkel W, Wright J, Zang H, Visser ME (2004) Large-scale geographical variation confirms that climate change causes birds to lay earlier. Proc R Soc Lond B 271(1549):1657-1662

Both C, Bouwhuis S, Lessells CM, Visser ME (2006) Climate change and population declines in a long-distance migratory bird. Nature 441(7089):81-83

Both C, van Asch M, Bijlsma RG, van den Burg AB, Visser ME (2008) Climate change and unequal phenological changes across four trophic levels: constraints or adaptations? J Anim Ecol 78: $1-3$

Charmantier A, McCleery RH, Cole LR, Perrins C, Kruuk LEB, Sheldon BC (2008) Adaptive phenotypic plasticity in response to climate change in a wild bird population. Science 320(5877): 800-803

Cresswell W, McCleery R (2003) How Great Tits maintain synchronization of their hatch date with food supply in response to longterm variability in temperature. J Anim Ecol 72(2):356-366
Crick HQP, Dudley C, Glue DE, Thomson DL (1997) UK birds are laying eggs earlier. Nature 388:526

de Heij ME, Ubels R, Visser GH, Tinbergen JM (2008) Female Great Tits Parus major do not increase their daily energy expenditure when incubating enlarged clutches. J Avian Biol 39(2):121-126

Dunn P (2004) Breeding dates and reproductive performance. Adv Ecol Res 35:69-87

Durant JM, Anker-Nilssen T, Stenseth NC (2003) Trophic interactions under climate fluctuations: the Atlantic puffin as an example. Proc R Soc Lond B 270(1523):1461-1466

Gaston AT, Gilchrist HG, Mallory ML, Smith PA (2009) Changes in seasonal events, peak food availability, and consequent breeding adjustment in a marine bird: a case of progressive mismatching. Condor 111(1):111-119. doi:10.1525/cond.2009.080077

Gienapp P, Visser ME (2006) Possible fitness consequences of experimentally advanced laying dates in Great Tits: differences between populations in different habitats. Funct Ecol 20(1):180 185

Gienapp P, Postma E, Visser ME (2006) Why breeding time has not responded to selection for earlier breeding in a songbird population. Evolution 60(11):2381-2388

Haywood S, Perrins CM (1992) Is clutch size in birds affected by environmental-conditions during growth? Proc R Soc Lond B 249(1325):195-197

Houghton JT, Ding Y, Griggs DJ, Noguer M, van der Linden PJ, Xiaosu D (2001) Climate change 2001: the scientific basis contribution of working group $i$ to the third assessment report of the intergovernmental panel on climate change (IPCC). Cambridge University Press, Cambridge

Husby A, Hille S, Visser ME (2011a) Testing mechanisms of Bergmann's rule: phenotypic but no genetic decline in body size in three passerine bird populations. Am Nat 178:202-213. doi: $10.1086 / 660834$

Husby A, Visser ME, Kruuk LEB (2011b) Speeding up microevolution: annual strength of selection and heritability are positively associated in a wild bird population. PLoS Biol 9:e1000585

Jenni L, Kéry M (2003) Timing of autumn bird migration under climate change: advances in long-distance migrants, delays in short-distance migrants. Proc R Soc Lond B 270(1523):14671471

Jenouvrier S, Caswell H, Barbraud C, Holland M, Stroeve J, Weimerskirch H (2009) Demographic models and IPCC climate projections predict the decline of an emperor penguin population. Proc Natl Acad Sci USA 106(6):1844-1847. doi:10. 1073/pnas.0806638106

Jonzen N, Hedenstrom A, Lundberg P (2007) Climate change and the optimal arrival of migratory birds. Proc R Soc Lond B 274(1607):269-274

la Sorte F, Thompson FR (2007) Poleward shifts in winter ranges of North American birds. Ecology 88:1803-1812. doi:10.1890/ 06-1072.1

Ludwig GX, Alatalo RV, Helle P, Linden H, Lindstrom J, Siitari H (2006) Short- and long-term population dynamical consequences of asymmetric climate change in black grouse. Proc R Soc Lond B 273(1597):2009-2016

Ludwig GX, Alatalo RV, Helle P, Siitari H (2010) Individual and environmental determinants of early brood survival in black grouse Tetrao tetrix. Wildl Biol 16:367-378

Matthysen E, Adriaensen F, Dhondt AA (2011) Multiple responses to increasing spring temperatures in the breeding cycle of blue and Great Tits (Cyanistes caeruleus, Parus major). Glob Change Biol 17(1):1-16. doi:10.1111/j.1365-2486.2010.02213.x

Monaghan P, Nager RG, Houston DC (1998) The price of eggs: increased investment in egg production reduces the offspring rearing capacity of parents. Proc R Soc Lond B 265:1731-1735 
Nager RG, Van Noordwijk AJ (1992) Energetic limitation in the egglaying period of Great Tits. Proc R Soc Lond B 249:259-263

Nager RG, Ruegger C, Van Noordwijk AJ (1997) Nutrient or energy limitation on egg formation: a feeding experiment in Great Tits. J Anim Ecol 66:495-507

Nielsen JT, Moller AP (2006) Effects of food abundance, density and climate change on reproduction in the sparrowhawk Accipiter nisus. Oecologia 149(3):505-518. doi:10.1007/s00442-0060451-y

Nilsson JA, Raberg L (2001) The resting metabolic cost of egg laying and nestling feeding in Great Tits. Oecologia 128(2):187-192

Parmesan C (2006) Ecological and evolutionary responses to recent climate change. Annu Rev Ecol Evol Syst 37:637-669

Pearce-Higgins JW, Yalden DW, Whittingham MJ (2005) Warmer springs advance the breeding phenology of golden plovers Pluvialis apricaria and their prey (Tipulidae). Oecologia 143(3): 470-476

Perrins C (1970) The timing of birds' breeding season. Ibis 112:242-255

Saether BE, Tufto J, Engen S, Jerstad K, Rostad OW, Skatan JE (2000) Population dynamical consequences of climate change for a small temperate songbird. Science 287:854-856

Saino N, Rubolini D, Lehikoinen E, Sokolov LV, Bonisoli-Alquati A, Ambrosini R, Boncoraglio G, Moller AP (2009) Climate change effects on migration phenology may mismatch brood parasitic cuckoos and their hosts. Biol Lett 5(4):539-541. doi: $10.1098 / \mathrm{rsbl} .2009 .0312$

Sanz JJ (2002) Climate change and breeding parameters of great and blue tits throughout the western Palaearctic. Glob Change Biol 8(5):409-422

Sanz JJ, Potti J, Moreno J, Merino S, Frias O (2003) Climate change and fitness components of a migratory bird breeding in the Mediterranean region. Glob Change Biol 9(3):461-472

Schaper SV, Dawson A, Sharp P, Gienapp P, Caro SP, Visser ME (2011) Increasing temperature, not mean temperature, is a cue for avian timing of reproduction. Am Nat (in press)

Schekkerman H, Beintema AJ (2007) Abundance of invertebrates and foraging success of Black-tailed Godwit Limosa limosa chicks in relation to agricultural grassland management. Ardea 95(1):39_ 54

Sheldon BC, Kruuk LEB, Merila J (2003) Natural selection and inheritance of breeding time and clutch size in the collared flycatcher. Evolution 57(2):406-420

Stevenson IR, Bryant DM (2000) Climate change and constraints on breeding. Nature 406:366-367

te Marvelde L, Schaper SV, Visser ME (2011a) A single long day triggers follicle growth in captive female Great Tits (Parus major) but does not affect laying dates in the wild. PLoS ONE (Submitted)

te Marvelde L, Webber SL, Meijer HAJ, Visser ME (2011b) Egg production is equally costly for early and late breeding freeliving Great Tits. Oecologia. doi:10.1007/s00442-011-2122-x

te Marvelde L, Webber SL, Meijer HAJ, Visser ME (2011c) Mismatched reproduction is energetically costly for chick feeding female Great Tits. Funct Ecol. doi:10.1111/j.1365-2435. 2011.01889.x

Teplitsky C, Mills JA, Alho JS, Yarrall JW, Merila J (2008) Bergmann's rule and climate change revisited: disentangling environmental and genetic responses in a wild bird population. Proc Natl Acad Sci USA 105(36):13492-13496

Thackeray SJ, Sparks TH, Frederiksen M, Burthe S, Bacon PJ, Bell JR, Botham MS, Brereton TM, Bright PW, Carvalho L, CluttonBrock T, Dawson A, Edwards M, Elliott JM, Harrington R, Johns D, Jones ID, Jones JT, Leech DI, Roy DB, Scott WA, Smith M, Smithers RJ, Winfield IJ, Wanless S (2010) Trophic level asynchrony in rates of phenological change for marine, freshwater and terrestrial environments. Glob Change Biol 16: 3304-3313

Thomas CD, Lennon JJ (1999) Birds extend their ranges northwards. Nature 399(6733):213

Thomas DW, Blondel J, Perret P, Lambrechts MM, Speakman JR (2001) Energetic and fitness costs of mismatching resource supply and demand in seasonally breeding birds. Science 291(5513):2598-2600

van Buskirk J, Mulvihill RS, Leberman RC (2009) Variable shifts in spring and autumn migration phenology in North American songbirds associated with climate change. Glob Change Biol 15:760-771

van Noordwijk AJ, McCleery RH, Perrins CM (1995) Selection of timing of great tit (Parus major) breeding in relation to caterpillar growth and temperature. J Anim Ecol 64:451-458

Verboven N, Verhulst S (1996) Seasonal variation in the incidence of double broods: the data hypothesis fits better than the quality hypothesis. J Anim Ecol 65:264-273

Verhulst S, Nilsson JA (2007) The timing of birds' breeding seasons: a review of experiments that manipulated timing of breeding. Philos Trans R Soc Lond B 363:399-410

Verhulst S, Tinbergen JM (2001) Variation in food supply, time of breeding, and energy expenditure in birds. Science 294(5542): U1-U1

Verhulst S, JHv Balen, Tinbergen JM (1995) Seasonal decline in reproductive success of the great tit: variation in time or quality? Ecology 76:2392-2403

Visser ME (2008) Keeping up with a warming world; assessing the rate of adaptation to climate change. Proc R Soc Lond B 275:649-659

Visser ME, Both C (2005) Shifts in phenology due to global climate change: the need for a yardstick. Proc R Soc Lond B 272:25612569

Visser ME, Lambrechts MM (1999) Information contraints in the timing of reproduction in temperate zone birds: Great and Blue Tits. In: Adams NJ, Slotow RH (eds) Proceedings of 22 international ornithology congress, Durban, pp 249-264

Visser ME, Lessells CM (2001) The costs of egg production and incubation in Great Tits (Parus major). Proc R Soc Lond B 268(1473):1271-1277

Visser ME, van Noordwijk AJ, Tinbergen JM, Lessells CM (1998) Warmer springs lead to mistimed reproduction in Great Tits (Parus major). Proc R Soc Lond B 265(1408):1867-1870

Visser ME, Adriaensen F, van Balen JH, Blondel J, Dhondt AA, van Dongen S, du Feu C, Ivankina EV, Kerimov AB, de Laet J, Matthysen E, McCleery R, Orell M, Thomson DL (2003) Variable responses to large-scale climate change in European Parus populations. Proc R Soc Lond B 270(1513):367-372

Visser ME, Holleman LJM, Gienapp P (2006) Shifts in caterpillar biomass phenology due to climate change and its impact on the breeding biology of an insectivorous bird. Oecologia 147(1): 164-172

Visser ME, Perdeck AC, van Balen JH, Both C (2009) Climate change leads to decreasing bird migration distances. Glob Change Biol 15(8):1859-1865. doi:10.1111/j.1365-2486.2009. 01865.x

Visser ME, Caro SP, van Oers K, Schaper SV, Helm B (2010) Phenology, seasonal timing and circannual rhythms: towards a unified framework. Philos Trans R Soc Lond B 365:3113-3127

Visser ME, Schaper SV, Holleman LJM, Dawson A, Sharp P, Gienapp P, Caro SP (2011) The effects of temperature and genetic background on timing of avian reproduction. Funct Ecol 25:868-877. doi:10.1111/j.1365-2435.2011.01844.x

Yom-Tov Y, Wright J (1993) Effect of heating nest boxes on egg laying in the blue tit (Parus caeruleus). Auk 110:95-99 